Int. J. Electrochem. Sci., 15 (2020) $3104-3118$

International Journal of

ELECTROCHEMICAL

SCIENCE

www.electrochemsci.org

\title{
Acidified Bamboo-Derived Activated Carbon/Manganese Dioxide Composite as a High-Performance Electrode Material for Capacitive Deionization
}

\author{
Rong Zhuang ${ }^{1, \#}$, Lele Xu ${ }^{1, \#}$, Da Li ${ }^{l}$, Noor Muhammad ${ }^{l}$, Jing Chen ${ }^{l}$, Yingchun Y ${ }^{l}$, Huaihe Song ${ }^{1}$, \\ Jianfeng $\mathrm{Ma}^{2}$, Xinge Liu ${ }^{2, *}$, Xiaohong Chen ${ }^{1, *}$ \\ ${ }^{1}$ State Key Laboratory of Chemical Resource Engineering, Beijing Key Laboratory of Electrochemical \\ Process and Technology for Materials, Beijing University of Chemical Technology, Beijing, 100029, \\ P. R. China \\ ${ }^{2}$ Kay Laboratory of Bamboo and Rattan Science and Technology, International Center for Bamboo \\ and Rattan, Beijing, 100102; 2 School of Materials Science \\ \# These authors contributed equally to this work. \\ *E-mail: chenxh@mail.buct.edu.cn
}

doi: $10.20964 / 2020.04 .23$

Received: 9 December 2019 / Accepted: 6 February 2020 / Published: 10 March 2020

Capacitive deionization (CDI) is an emerging desalination technology which employs high surface area porous electrode materials to eliminate ions from water by electrosorption. Herein, we propose an acidified bamboo-based activated carbon $\left(\mathrm{BAC}_{\mathrm{a}}\right) /$ manganese dioxide $\left(\mathrm{MnO}_{2}\right)$ composite synthesize by a simple co-precipitation technique. Bamboo-based activated carbon exhibit high electrical conductivity, hierarchical pore structure, and large specific surface area, due to which it is regarded as a promising candidate for seawater desalination. In this work after acidification, significant amounts of oxygencontaining functional groups are introduced onto the surface of the carbon, which enhanced the hydrophilicity of whole composite, while the $\mathrm{MnO}_{2}$ nanoparticles with sufficient ion migration channels provide a high adsorption capability and fast reaction kinetics. Consequently, the synthesized $\mathrm{BAC}_{\mathrm{a}} / \mathrm{MnO}_{2}$ composite achieves a tremendous specific capacitance of $158 \mathrm{~F} \mathrm{~g}^{-1}$ at $10 \mathrm{mV} \mathrm{s}^{-1}$, excellent electrosorption capacity of $10.3 \mathrm{mg} \mathrm{g}^{-1}$, and outstanding recyclability in the application of CDI, which is in comparison better than that of bare bamboo-based activated carbon electrode. The present study endorses the promising application of the low-cost high-performance $\mathrm{BAC}_{\mathrm{a}} / \mathrm{MnO}_{2}$ in capacitive deionization.

Keywords: biomass, activated carbon, acidification, manganese dioxide, capacitive deionization 
(C) 2020 The Authors. Published by ESG (www.electrochemsci.org). This article is an open access article distributed under the terms and conditions of the Creative Commons Attribution license (http://creativecommons.org/licenses/by/4.0/). 